\title{
EXOSTOSIS FORMATION AFTER TRAUMATIC AVULSION OF THE ANTERIOR INFERIOR ILIAC SPINE
}

\author{
Report of Two Cases
}

\author{
M. H. IRVING, LiVERPOOL, ENGLAND \\ From the Department of Orthopaedic Surgery, Liverpool Royal Infirmary
}

Avulsion of tendons from their attachment to the pelvis is well recognised and often affects the anterior superior iliac spine and the ischial tuberosity. Detachment of the anterior inferior iliac spine by the rectus femoris muscle occurs less often, and although mentioned in textbooks (Watson-Jones 1955, Köhler 1956, Wiles 1960), it is only occasionally described in the literature (Corlette 1927, Pezcoller 1931, Hanke 1932, Rothbart 1932, Weitzner 1935). The present cases illustrate the development of an exostosis attached to the pelvis which occurred after avulsion of the apophysis of the anterior inferior iliac spine.

\section{CASE REPORTS}

Case 1-A boy of fourteen felt his left thigh "give way" while running. There was some pain in the upper thigh which subsided but returned three weeks later after he had landed heavily on his feet while somersaulting in the gymnasium.

Examination a week later showed full movement of both hips, with slight pain on full flexion of the left hip. He could walk without difficulty and the quadriceps muscle appeared

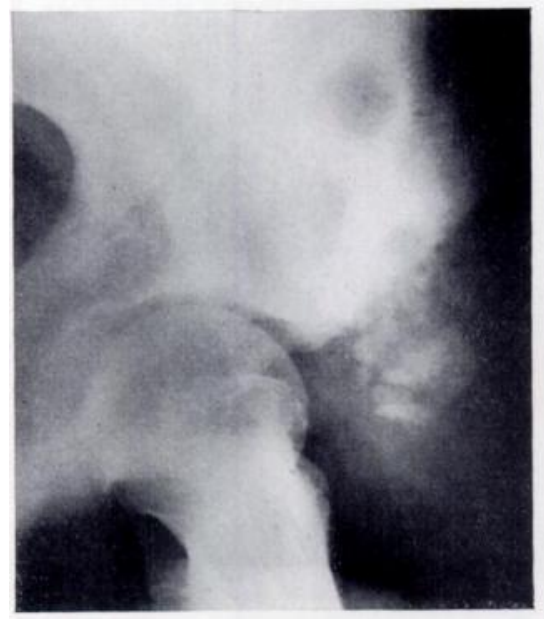

Fig. 1

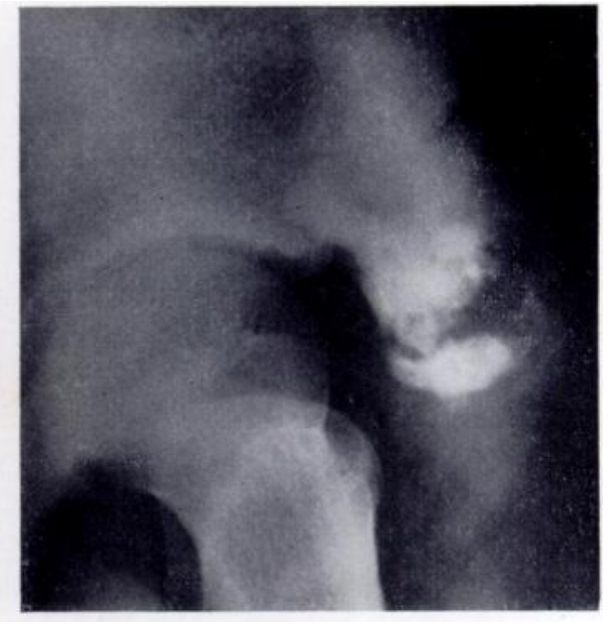

Fig. 2

Case 1. Figure 1-Radiograph showing avulsion of anterior inferior iliac spine and patchy calcification four and a half weeks after the original injury. Figure 2-Radiograph showing the exostosis that developed later.

normal. Radiographs showed that the anterior inferior iliac spine had been avulsed and there was evidence of patchy calcification, presumably in the surrounding haematoma (Fig. 1). The patient was advised to rest and to avoid athletics for a few weeks. Two weeks later he was free of symptoms and was discharged.

Six months later the boy was brought back on account of a limp, with difficulty in running even a short distance. On examination a hard swelling was felt attached to the pelvis in the 
region of the anterior inferior iliac spine. Although there was full flexion of the hip there was moderate limitation of rotation and abduction. Radiographs showed an exostosis attached to the pelvis at the site of the anterior inferior iliac spine, the apex of which showed patchy calcification (Fig. 2). The exostosis was removed because it restricted movement at the hip. The mass was firmly joined to the pelvis and was covered with periosteum. The two avulsed heads of the rectus femoris muscle lay in a mass of fibrous tissue, unattached to bone, distal

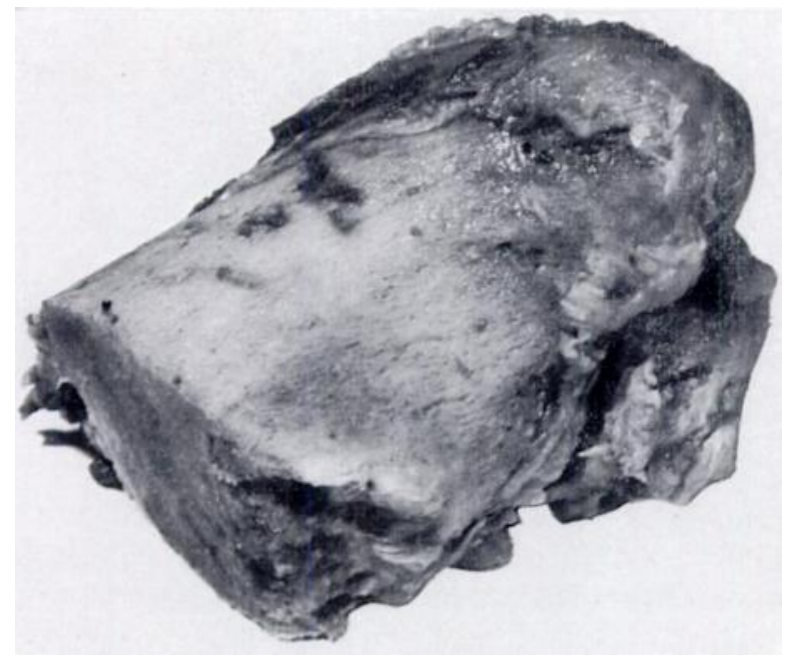

FIG. 3

Case 1-Photograph of the exostosis.

to the apex of the exostosis. No attempt was made to reattach the tendons to the pelvis. Recovery was uneventful and the patient was discharged, having regained a full range of movement of the hip. His progress was observed at frequent intervals, and although he remained free of symptoms there was clinical and radiological evidence of recurrence of the exostosis. Pathological findings-Naked-eye examination of the specimen (Fig. 3) showed that it consisted of compact bone covered by periosteum. The apex appeared to be of cartilage containing islands of bone. Radiographs taken of thick longitudinal sections of the specimen confirmed these observations.

On histological examination the specimen consisted of dense trabecular bone with Haversian systems similar to normal cortical bone. The apex consisted of a cartilaginous cap which included islands of bone around which ossification was occurring. An additional finding in the cartilaginous cap was a cleft lined by synovial membrane, at right angles to the long axis of the exostosis and similar to a pseudarthrosis.

Case 2-Clinical details of this patient, seen in 1932, are not available. The radiologist reported that the exostosis (Fig. 4) was the result of traumatic avulsion of the anterior inferior iliac spine in a patient of fifteen. The radiograph showed a bony mass resembling that described in Case 1, though not so large.

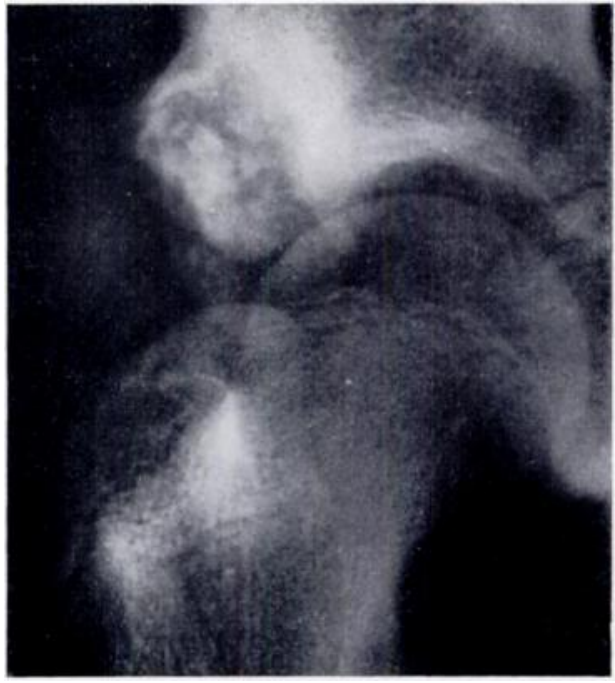

FIG. 4

Case 2-Radiograph of the exostosis. 


\section{DISCUSSION}

The principal cause of avulsion of tendons from the pelvis is violent muscular exertion such as may occur in sporting activities. The condition usually occurs in young people before the apophyses to which the tendons are attached have fused with the main body of the pelvis, but Rothbart (1932) reported a case of avulsion of the anterior inferior iliac spine in a mentally defective person aged thirty-two.

The present cases cannot be regarded as myositis ossificans in the rectus femoris muscle because the shape of the ossified mass in the radiographs differs from that described in such cases by Goodwin (1959); and in Case 1 it was shown at operation that the rectus femoris had been avulsed and showed no evidence of myositis ossificans.

The exostosis of the anterior inferior iliac spine described by Köhler (1956), and considered typical, may be similar to those described here, but it appears remarkably like the cases of myositis ossificans described by Goodwin (1959). Unfortunately Köhler did not include a lateral radiograph, by which the condition can be differentiated. Köhler also described the macroscopic appearances of these exostoses as "tubular excrescences" in which the groove was the site for the course of the muscle or tendon. These findings are in contrast to the specimen in Case 1, and give the impression, as Köhler himself suggested, that the exostoses he described were caused by myositis ossificans.

The presence in Case 1 of a cartilaginous cap overlying solid trabecular bone, along with convincing evidence that the avulsed heads of the rectus femoris muscle lay distal to the lesion, are sufficient grounds for considering that true exostosis formation has occurred. The similar history and radiological findings are grounds for including Case 2 as another example. The cleft lined by synovial membrane indicates the formation of a pseudarthrosis stimulated by movement occurring at the distal end of the exostosis. A similar feature was noted by Goodwin (1959).

\section{SUMMARY}

Two cases are described of exostosis of the anterior inferior iliac spine after traumatic avulsion of the apophysis at this site by the rectus femoris muscle.

I am indebted to Mr Norman W. Roberts for his advice and permission to publish Case 1, and to Dr Norah Walker for the details of Case 2.

\section{REFERENCES}

CORlette, C. E. (1927): Fracture of the Anterior Inferior Spine of the Ilium. Medical Journal of Australia, ii, 682.

Goodwin, M. A. (1959): Myositis Ossificans in the Region of the Hip-joint. British Journal of Surgery, 46, 547.

HANKE, H. (1932): Zur Kenntnis der isolierten Abrissfraktur der unteren Spina anterior ossis ilei. Archiv für Orthopädische und Unfallchirurgie, 31, 377.

KöHLER, A. (1956): Borderlands of the Normal and Early Pathologic in Skeletal Roentgenology. Tenth edition. English Translation edited by J. T. Case. New York: Grune and Stratton.

RothBaRT, L. (1932): Abrissfraktur der Spina iliaca ant. inf. Zentralblatt für Chirurgie, 59, 781.

Pezcoller, A. (1931): Le Fratture della spina iliaca anteriore inferiore. Quoted by Robertson, R. C. (1935): Journal of Bone and Joint Surgery, 17, 1,045.

Watson-Jones, Sir R. (1955): Fractures and Joint Injuries. Fourth edition. Edinburgh and London: E. \& S. Livingstone Ltd.

WeitzNer, I. (1935): Fracture of the Anterior Superior Spine of the Ilium in one Case, and Anterior Inferior in Another Case. American Journal of Roentgenology, 33, 39.

Wiles, P. (1960): Fractures, Dislocations and Sprains. London: J. \& A. Churchill Ltd. 